
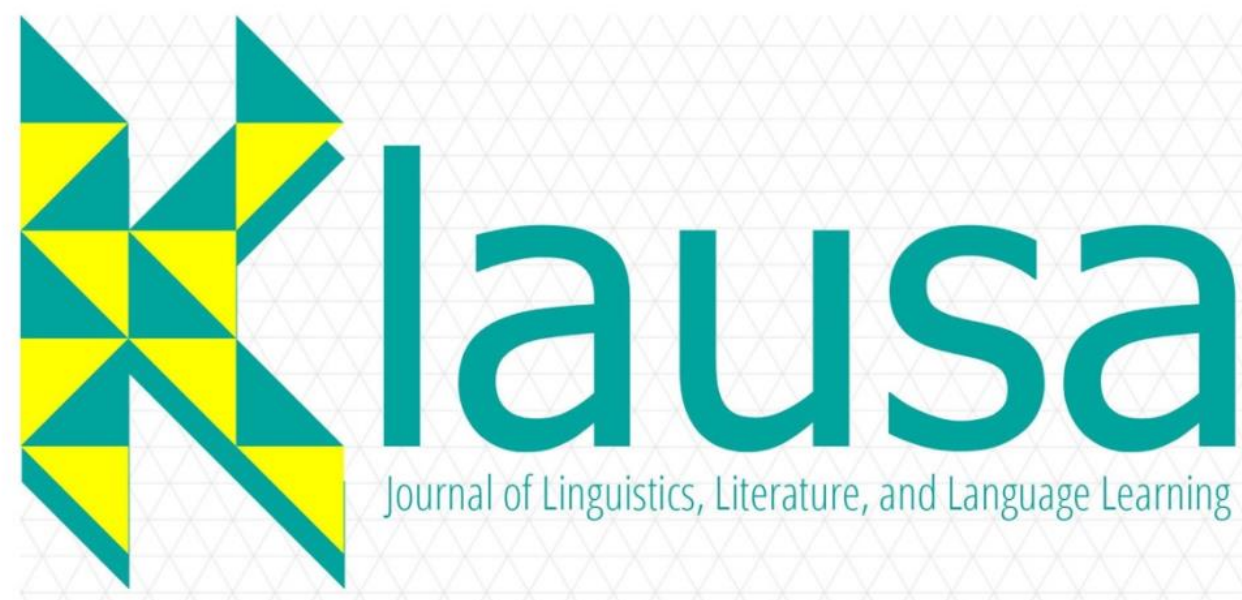

ISSN 2620-9527

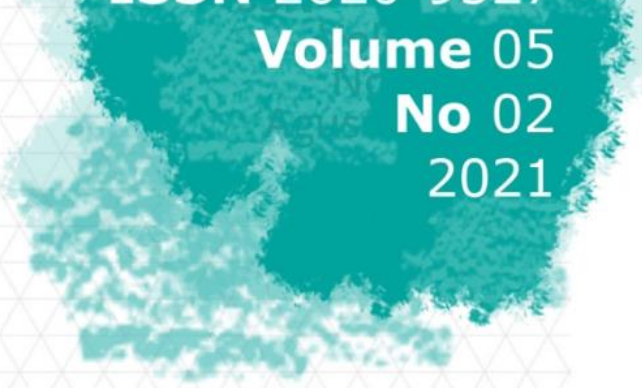

Journal of Linguistics, Literature, and Language Learning

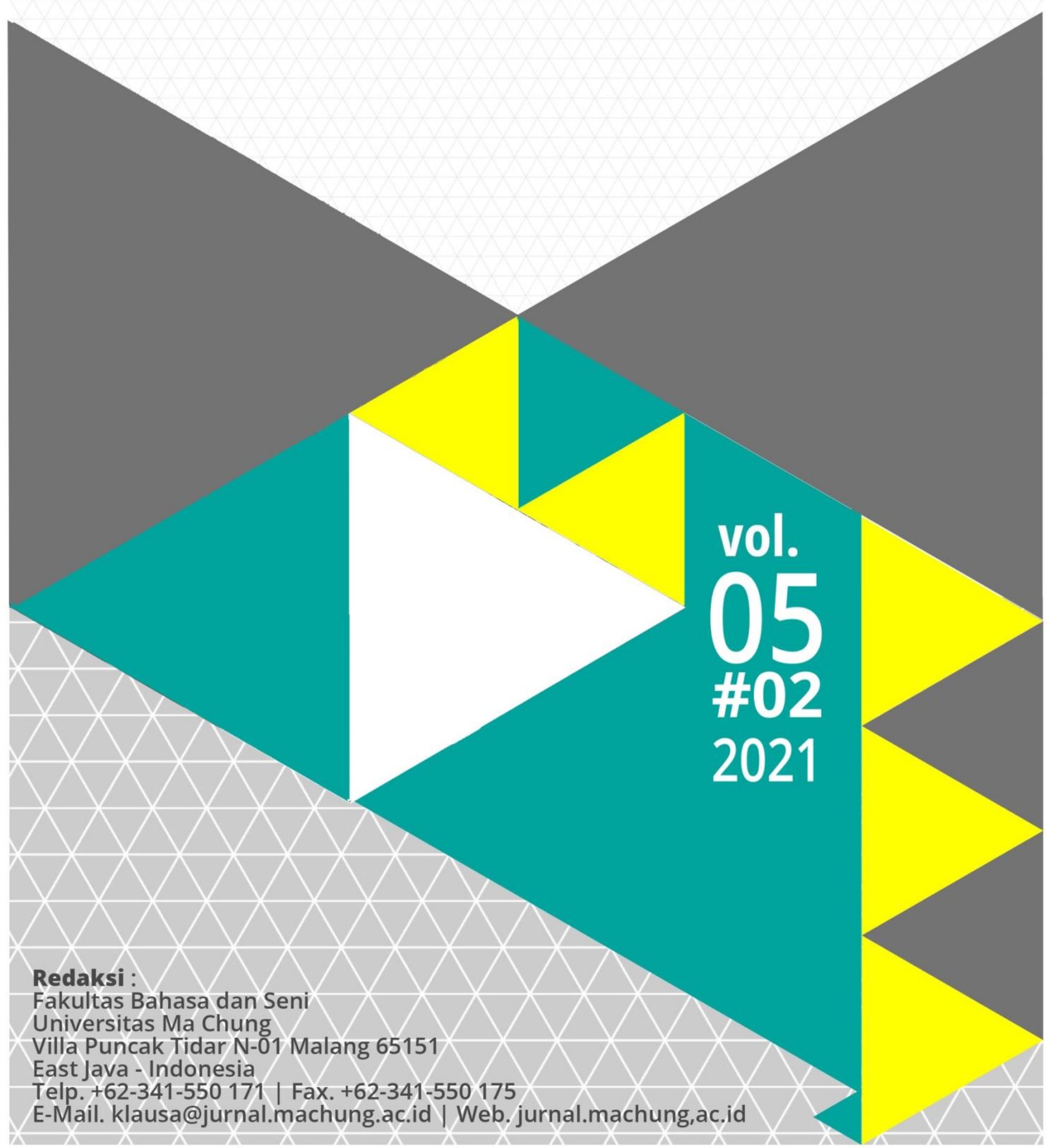


ISSN: $2301-4822(p)$

2620-9527 (e)

DOI:

\section{Kajian Linguistik, Pembelajaran}

Bahasa, dan Sastra

\section{Editorial Team}

Editor-in-Chief:Dr. Daniel Ginting

Journal Manager:Wawan Eko Yulianto, Ph.D.

Editors: Prof. Dr. Patrisius I. Djiwandono

Lilis Lestari Wilujeng, M.Hum.

Reviewers:F.X Dono Sunardi, M.A.

Dhatu Sitaresmi, MTCSOL.

Anggrah Diah Arlinda, MTCSOL.

Yohanna Nirmalasari, S.Pd., M.Pd.

Prof. A. Effendi Kadarisman, Ph.D.

Sisilia Halim, Ph.D.

Dr. Mundi Rahayu

Dr. Ross Wood

Dr. Leticia Araceli Salas Serrano

Publisher: Faculty of Language and Arts

Universitsas Ma Chung

Address: The Faculty of Language and Arts

$$
\begin{aligned}
& \text { Ma Chung University } \\
& \text { Villa Puncak Tidar N-01 (65151) } \\
& \text { Malang, East Java, Indonesia } \\
& \text { Email: jurnal.klausa@machung.ac.id }
\end{aligned}
$$

Frequency: Twice a year 


\section{CONTENTS}

FOREWORD

iii

SOLIDARITY IN THE TOURING NARRATIVE OF S.U.U.A.L (SCOOTER UIN ULUL ALBAB)

MALANG VESPA COMMUNITY: A CRITICAL DISCOURSE ANALYSIS APPROACH

Yunia Dewi Fathmawati ${ }^{1}$

THE ROLE OF PARENTAL GUIDANCE ON VOCABULARY ACHIEVEMENT IN AN INDONESIAN EFL ELEMENTARY EDUCATION SETTING

Christian Edison Bani ${ }^{1}$, Sahiruddin ${ }^{2}$, Ika Nurhayani ${ }^{3}$

MENELAAH POTENSI SASTRA PARIWISATA DI TELAGA SARANGAN

Ardi Wina Saputra ${ }^{1}$, Rustiati ${ }^{2}$

MAKNA KULTURAL DALAM LEKSIKON PERHIASAN PENGANTIN SUNDA PRIANGAN (KAJIAN ETNOLINGUISTIK)

Elda Mnemonica Rosadi ${ }^{1}$, Retty Isnendes ${ }^{2}$, Mahmud Fasya ${ }^{3}$

133

THE ENVIRONMENTAL ASPECTS OF ALEXANDRE DUMAS'

THE COUNT OF MONTE CRISTO

Gusti Ayu Made Suarniti ${ }^{1}$ 


\title{
MAKNA KULTURAL DALAM LEKSIKON PERHIASAN PENGANTIN SUNDA PRIANGAN: KAJIAN ETNOLINGUISTIK
}

\author{
Elda Mnemonica Rosadi ${ }^{1}$, Retty Isnendes ${ }^{2}$, Mahmud Fasya ${ }^{3}$ \\ 1Universitas Pendidikan Indonesia, Indonesia, eldamnemonica@upi.edu \\ 2Universitas Pendidikan Indonesia, Indonesia, retty.isnendes@upi.edu \\ 3Universitas Pendidikan Indonesia, Indonesia, mahmud_fasya@upi.edu
}

\begin{abstract}
ABSTRAK
Pernikahan adat Sunda khususnya di daerah Priangan memiliki perhiasan pengantin Sunda yang kaya akan makna kultural Penelitian ini bertujuan untuk mendeskripsikan makna leksikal dan makna kultural dalam perhiasan pengantin putri Sunda Priangan. Metode yang digunakan dalam penelitian ini yaitu kualitatif deskriptif dengan pendekatan etnolinguistik. Data penelitian ini berupa ekspresi verbal dan non-verbal yang ada dalam perhiasan pengantin putri Sunda Priangan. Sumber penelitian ini berasal dari informan pemilik usaha rias pengantin dan perias pengantin di daerah Garut dan Bandung.Metode yang digunakan dalam pengumpulan data yaitu dengan wawancara dan observasi. Hasil penelitian Terdapat 13 data verbal yang dijadikan sebagai sumber data dalam leksikal perhiasan pengantin Sunda, Adapun secara kultural tradisi ini dapat terlihat dari salah satu aspek spiritual yaitu menjadi sebuah harapan dan doa dari para leluhur dan masyarakat Sunda
\end{abstract}

Kata Kunci: makna kultural, leksikon, etnolinguistik, perhiasan, sunda

\section{PENDAHULUAN}

Tatanan kehidupan sehari-hari masyarakat selarasnya harus mengikuti adat istiadat yang ada. Terlebih, Indonesia merupakan negara yang mempunyai kekayaan budaya dari setiap pelosok daerahnya. Dalam hal ini, budaya tentunya memiliki makna yaitu sebuah sistem yang meliputi kehidupan sehari-sehari yang mana berkembang luas di masyarakat dengan menambahkan berbagai unsur dan diturunkan dari satu generasi ke generasi lainnya agar dapat mewujudkan dan melangsungkan nilai-nilai budaya tersebut. 
Sementara itu, menurut Koentjaraningrat (2011) kebudayaan adalah suatu keseluruhan manusia berupa kelakuan dan hasil yang didapatkan dengan belajar sehingga semuanya tersusun dalam kehidupan masyarakat. Adapun budaya Sunda yang dibahas dalam penelitian ini yaitu, sebuah tatanan dari cara berperilaku masyarakat yang terdapat di dataran tanah Sunda serta dapat menghayati kepercayaan, mata pencaharian, kesenian, sistem kekerabatan, bahasa dan adat istiadat (Ramadhanty, 2019). Dari pemaparan sebelumnya, dapat disimpulkan bahwa kebiasaan yang dilakukan oleh masyarakat sejak lahir hingga sekarang dalam memenuhi kebutuhan hidupnya disebut sebagai kebudayaan.

Unsur-unsur kebudayaan pun terbagi atas tujuh unsur yaitu meliputi bahasa,sistem religi,organisasi sosial, sistem pengetahuan, kesenian, sistem ekonomi dan teknologi (Koentjaraningrat, 2005). Salah satu sistem teknologi yang menarik dibahas adalah pakaian dan perhiasan yang dikenakan oleh masyarakat Sunda. Khususnya perhiasan atau aksesoris yang digunakan dalam adat pernikahan Sunda.

Pernikahan adat Sunda di Jawa Barat sangat bervariasi, hal ini disebabkan oleh keberagaman masyarakat yang berasal dari berbagai macam etnis yang berbeda. Hal lain yang mempengaruhi adalah letak geografis, adat-istiadat setiap kelompok dan tingkatan status ekonomi dari masyarakatnya. Pernikahan adat Sunda di Jawa Barat terdiri dari pakaian pernikahan khas Kaleran, Cirebon dan Priangan.

Penelitian ini berfokus pada perhiasan yang dipakai dalam pernikahan adat Sunda Priangan yang meliputi beberapa daerah yaitu Bandung, Sumedang,Tasikmalaya,dan Cianjur yang mana daerah ini berpusat di Bandung. Priangan utamanya dijadikan sebagai kiblat dari daerah lainnya karena merupakan pusat daerah pemerintahan. Daerah Priangan dipilih karena terlepas dari pengaruh Eropa dan dianggap paling sesuai dengan karakteristik daerah di Jawa Barat. Dalam adat pernikahan Sunda terdapat unsur pokok untuk menunjang pernikahan tersebut seperti adanya tata rias pengantin, pakaian pengantin dan perhiasan.

Peneliti berfokus pada leksikon dan makna kultural yang ada di dalam perhiasan pengantin wanita Sunda. Menurut Kridalaksana, leksikon adalah kumpulan komponen bahasa yang memuat semua informasi tentang makna dan pemakaian kata dalam suatu bahasa (Hardiyanto, 2008). Sedangkan, menurut Saifullah (2018) leksikon adalah suatu wadah yang menyimpan makna dari ekspresi sebuah bahasa yang maknanya tidak dapat ditentukan berdasarkan arti unsur pokoknya. Sementara itu, leksikon disusun berdasarkan kegunaan dari leksikon itu sendiri. Seperti contoh, penutur mengakses leksikon dari bunyi atau bentuk tulisan berdasarkan leksikon yang didengar atau dibacanya sehingga penutur mengakses leksikon tersebut melalui makna. Dalam penelitian ini, peneliti berfokus pada dua arah leksikon yaitu secara bentuk dan makna. Secara bentuk, leksikon diakses dari bunyinya (fonologi), tulisan, onset dan rhyme, bentuk terikat yang bisa diakses dari satu dengan yang lainnya. Sedangkan berdasarkan makna, terutama makna intrinsik ditinjau dari suatu kata pada leksikon dan lokasinya 
dalam bidang semantik harus diidentifikasikan sehingga membuat kata yang memiliki makna berkaitan dan dapat saling diakses. Makna yang ada di dalam sebuah tradisi pun dapat berupa verbal maupun nonverbal. Menurut Abdullah (dalam Rudiyanto, Rais, \& Purnanto, 2020) makna kultural merupakan makna yang dimiliki oleh bahasa sesuai dengan konteks budaya penuturnya yang berhubungan dengan sistem pengetahuan (cognitive system) yang kemudian tercermin dalam pola pikir (mindset), pandangan hidup (way of life), dan pandangan terhadap dunia (world view). Maka dari itu, penelitian ini berfokus pada leksikon dan makna kultural yang terdapat pada aksesoris pengantin wanita Sunda priangan dengan pendekatan etnolinguistik.

Etnolinguistik merupakan suatu studi mengenai bahasa dan budaya atau bisa disebut juga sebagai antropolinguistik. Studi ini dapat digunakan untuk mengkaji bahasa, kebudayaan, dan aspek-aspek lain kehidupan manusia, pusat perhatian atau perhatian utama antropolinguistik (Duranti dalam Sibarani, 2015). Hal ini pun ditekankan pada tiga topik penting yaitu performansi (performance), indeksikalitas (indexicality), partisipasi (participation). Melalui konsep performansi, bahasa dipahami dalam proses kegiatan, tindakan dan pertunjukan komunikatif, yang membutuhkan kreativitas. Bahasa sebagai unsur lingual yang menyimpan sumber-sumber kultural tidak dapat dipahami secara terpisah dari pertunjukan atau kegiatan berbahasa tersebut. Dalam mengkaji penggunaan bahasa, antropologis memegang dan menerapkan tiga parameter yakni (1) keterhubungan (interconnection), (2) kebernilaian (valuability), dan (3) keberlanjutan (continuity). Dalam penelitian ini, peneliti fokus kepada kebernilaian yang mana dalam hal ini, kebernilaian memperlihatkan makna atau fungsi, sampai ke nilai atau norma, serta akhirnya sampai pada kearifan lokal aspek-aspek yang diteliti (Sibarani, 2015).

Adapun penelitian terdahulu yang menjadi sumber rujukan penelitian yaitu, Strengthening Cultural Values Through Innovative Learning of Sunda Siger Bridal Makeup in West Java Vocational Education (Lestari \& Saripah, 2019) yang berfokus pada metode pembelajaran terhadap tata rias pengantin siger Sunda yang dilaksanakan di lembaga pendidikan vokasi Jawa Barat, selain itu penelitian tersebut juga berfokus pada nilai-nilai yang terdapat dalam siger Sunda. Selanjutnya, Tinjauan Etnolinguistik : Makna Kultural Dalam Tradisi "Sranan" Sebagai Wujud Kearifan Lokal Masyarakat Petani Pegunungan Di Kebumen (Rudiyanto, Rais, \& Purnanto, 2020) penelitian ini berfokus pada makna kultural yang terdapat pada tradisi sranan. Hasil penelitian ini berupa makna kultural yang terdapat dalam tradisi sranan diantaranya (1) tradisi sranan sebagai bentuk persembahan kepada penguasa sawah (Dewi Sri) agar terhindar dari segala macam hama yang merusak tanaman, (2) sebagai perantara untuk meminta keselamatan kepada Tuhan, dan (3) sebagai permohonan agar diberi rezeki yang lancar serta hasil panen yang melimpah. Kajian Makna Pada Aksesori Pakaian adat Lampung Pepadun (Roveneldo, 2018) berfokus pada penamaan aksesori dalam pernikahan adat lampung pepadun yang dikaji secara semantik leksikal dan makna kultural yang ditinjau dari teori semiotik serta sikap masyarakat terhadap eksistensi pakaian adat lampung dalam upacara pernikahan. 
Perancangan Informasi Mengenai Pakaian Pernikahan Adat Sunda Priangan Melalui Media Buku Informasi (Ramadhanty, 2019) berfokus pada penyampaian informasi mengenai pakaian pernikahan Sunda Priangan secara lengkap beserta maknanya yang ditinjau dari sudut pandang studi desain komunikasi visual. Selanjutnya, Makna Kultural Dalam Satuan Lingual Rias Pengantin Pemalang Putri (Amelia \& Syaifudin, 2020) penelitian ini berfokus pada bentuk satuan lingual dalam rias pengantin Pemalang Putri dan makna kultural dari satuan lingual rias pengantin Pemalang Putri.

Bersumber pada beberapa referensi diatas, peneliti tertarik untuk meneliti lebih lanjut mengenai makna kultural pada leksikon perhiasan pengantin wanita Sunda Priangan yang ditinjau berdasarkan pandangan masyarakat, pandangan hidup serta pola pikir masyarakat Sunda. Hal ini dilakukan agar masyarakat Sunda, terlebih para generasi muda mengetahui makna yang sangat sakral dalam penggunaan perhiasan pernikahan wanita Sunda.

\section{METODE PENELITIAN}

Penelitian ini merupakan penelitian lapangan yang berfokus pada makna kultural pada leksikon perhiasan pengantin Sunda Priangan. Selain itu, penelitian ini menggunakan metode deskriptif kualitatif dengan pendekatan etnolinguistik. Pengumpulan data dalam penelitian ini terdiri dari data verbal dan non-verbal.Sumber pengambilan data verbal yaitu berupa tuturan informasi dalam bentuk satuan lingual kata, frasa, dan klausa maupun kalimat yang terdapat dalam perhiasan pengantin wanita Sunda Priangan. Kalimat merupakan salah satu bentuk kegiatan berbahasa, begitupun dengan kata, frasa dan klausa (Nirmalasari, Pola Kalimat Bahasa Indonesia Tulis Pembelajar BIPA Tingkat Pemula Asal Tiongkok Di Universitas Ma Chung Tahun 2018, 2018). Sedangkan data non-verbal berupa simbol-simbol yang berupa benda-benda yang terdapat dalam perhiasan pengantin wanita. Sumber data berasal dari informan yang terpilih serta dokumen lain sebagai pendukung. Sumber Data yang diperoleh dari informan yang terpilih yaitu Fauzia Ulfa selaku pemilik usaha tata rias pengantin Fauzia Make Up di Desa Sukahaji,Garut dan Nuril Badyah selaku perias pengantin di Cibiru, Bandung Timur.

Dalam menentukan informan mana yang akan dipilih, peneliti menggunakan teknik purposive sampling dan snowball sampling. Teknik purposive sampling merupakan teknik pengambilan sampel sumber data dengan pertimbangan tertentu, misalnya orang tersebut dianggap paling tahu atas segala informasi yang peneliti harapkan. Sedangkan, snowball sampling yaitu teknik pengambilan sampel sumber data yang awalnya jumlahnya sedikit kemudian menjadi banyak (Sugiyono, 2009). Selain itu, penelitian ini juga menggunakan instrumen utama dan instrumen penunjang. Menurut Nirmalasari (2020) instrumen utama merupakan instrumen kunci yang memiliki peran sebagai partisipan aktif dalam pengumpulan data. Dalam penelitian ini, instrumen penunjangnya 
adalah narasumber, sedangkan instrumen pendukung merupakan leksikon dalam berbagai macam perhiasan pengantin Sunda Priangan.

Teknik yang dipakai dalam pengumpulan data menggunakan teknik observasi dan wawancara. Selanjutnya, metode triangulasi digunakan dalam validitas data yang berupa sumber data dan pengumpulan data (Santosa, 2017). Terakhir, data dianalisis dengan cara diorganisasikan dan memilahnya menjadi satuan yang dapat dikelola, mensintesiskannya, mencari, dan menemukan pola, menemukan apa yang penting dan dipelajari serta memutuskan yang dapat diceritakan kepada orang lain (Moleong, 2005).

\section{TEMUAN DAN PEMBAHASAN}

Hasil dalam penelitian ini mencakup dua hal yang sesuai berdasarkan rumusan masalah dan tujuan penelitian yang akan dibahas, yaitu leksikon yang ada pada perhiasan pengantin wanita Sunda Priangan dan makna kultural pada perhiasan pengantin putri Sunda Priangan .Dalam pengumpulan sumber data, telah dikumpulkan ada 13 data berupa leksikon dari setiap perhiasan pengantin wanita Sunda Priangan serta kategori dan arti secara leksikal. Makna kultural yang tercermin dalam penggunaan perhiasan pengantin putri Sunda Priangan merupakan bentuk atas doa dan harapan leluhur serta masyarakat Sunda untuk pengantin putri.

\section{Leksikon Pada Perhiasan Pengantin Putri Sunda Priangan}

Dalam pernikahan sunda, terutama perhiasan yang dikenakan pengantin putri memiliki jenis yang bermacam-macam. Adapun berbagai leksikon perhiasan yang dikenakan oleh pengantin putri Sunda Priangan yang ditulis, sebagai berikut.

Tabel 1. Arti Leksikal dalam Leksikon Aksesoris Pengantin Wanita Sunda

\begin{tabular}{|c|c|c|c|c|}
\hline No & Kategori & $\begin{array}{l}\text { Nama } \\
\text { Aksesoris }\end{array}$ & Fonetis & Arti Leksikal \\
\hline 1 & Kata & Gelung & [gclun] & sanggul \\
\hline 2 & Kata & Mangle & [manle] & $\begin{array}{l}\text { Kumpulan dari } \\
\text { untaian bunga } \\
\text { sedap malam. }\end{array}$ \\
\hline 3 & Kata & Siger & [sigcr] & $\begin{array}{l}\text { Mahkota/penghi } \\
\text { as kepala }\end{array}$ \\
\hline 4 & Kata majemuk & $\begin{array}{l}\text { Kembang } \\
\text { goyang }\end{array}$ & $\begin{array}{l}\text { [kcmban } \\
\text { goyan] }\end{array}$ & Penghias kepala \\
\hline 5 & Kata & Giwang & [giwan] & $\begin{array}{l}\text { Dipasangkan di } \\
\text { kuping } \\
\text { pengantin } \\
\text { wanita, biasanya } \\
\text { milik pribadi }\end{array}$ \\
\hline
\end{tabular}




\begin{tabular}{|c|c|c|c|c|}
\hline 6 & Kata & Bros & [bros] & $\begin{array}{l}\text { Perhiasan yang } \\
\text { terbuat dari } \\
\text { emas,perak atau } \\
\text { logam }\end{array}$ \\
\hline 7 & Kata & Benten & [benten] & $\begin{array}{l}\text { Ikat pinggang } \\
\text { yang terbuat } \\
\text { dari emas atau } \\
\text { perak }\end{array}$ \\
\hline 8 & Kata majemuk & $\begin{array}{l}\text { Garuda } \\
\text { mungkur }\end{array}$ & $\begin{array}{l}\text { [garuda } \\
\text { munkur] }\end{array}$ & $\begin{array}{l}\text { Hiasan kepala } \\
\text { bagian belakang }\end{array}$ \\
\hline 9 & Kata majemuk & Wajit turih & [wajit turih] & $\begin{array}{l}\text { Daun sirih } \\
\text { berbentuk } \\
\text { berlian }\end{array}$ \\
\hline 10 & Kata majemuk & Panetep bunga & [panctcp buna] & Tutup sanggul \\
\hline 11 & Kata majemuk & $\begin{array}{l}\text { Kembang } \\
\text { tanjung }\end{array}$ & 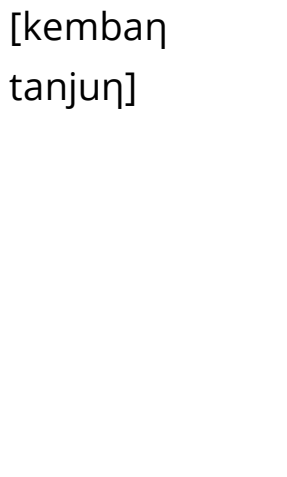 & $\begin{array}{l}\text { Aksesoris yang } \\
\text { terbuat dari } 6 \\
\text { bunga yang } \\
\text { dipasangkan } \\
\text { pada bagian } \\
\text { sanggul bagian } \\
\text { belakang siger } \\
\text { (mahkota) }\end{array}$ \\
\hline 12 & Kata majemuk & Mayang sari & [mayan sari] & $\begin{array}{l}\text { Untaian bunga } \\
\text { pendek yang } \\
\text { dipasang di } \\
\text { belakang telinga } \\
\text { sebelah kiri }\end{array}$ \\
\hline 13 & Kata & Ronce & [roncc] & $\begin{array}{l}\text { Aksesoris yang } \\
\text { terbuat dari } \\
\text { rangkaian bunga }\end{array}$ \\
\hline
\end{tabular}

\section{Makna Kultural dalam Perhiasan Pengantin Putri Sunda Priangan}

Harapan serta doa yang ditujukan kepada sang pengantin putri dalam menjalankan rumah tangga ada di dalam perhiasan yang digunakan oleh pengantin putri Sunda Priangan. Perhiasan pengantin putri Sunda dijadikan sebagai bentuk upaya atas harapan dan doa-doa serta tujuan dari peran seorang istri yang telah diturunkan turuntemurun dari budaya Sunda sendiri. Adapun leksikon-leksikon yang ada dalam penamaan perhiasan pengantin Sunda tersebut mengandung makna simbolis dan makna kultural yang diekspresikan secara non-verbal dalam konteks kebahasaan dan 
budaya Sunda di Priangan. Berikut makna kultural dalam perhiasan yang digunakan oleh pengantin putri Sunda.

Pertama, siger [sigcr] yang digunakan sebagai hiasan kepala seperti mahkota.Perhiasan ini yang menjadi sorotan utama dalam pernikahan adat Sunda. Pada umumnya, siger Sunda dibuat dari campuran logam dan memiliki berat sekitar 1,5-2 kg. Dalam adat Sunda Priangan, siger bentuk siger menyerupai segitiga keatas yang memiliki makna kultural tentang kehidupan yang harus terus memuncak dan pada akhirnya kehidupan yang sesungguhnya saat kita kembali kepada yang diatas Yang Maha Kuasa. Siger Sunda adat Priangan terinspirasi dari tokoh Subardha dan Srikandi yang mempunyai sifat anggun,cantik dan pemberani. Selain itu, mereka juga disenangi oleh masyarakat Sunda. Hal ini memberikan makna terhadap siger sendiri sebagai kesempurnaan seorang wanita serta harapan atas rasa hormat, kebijaksanaan dan kearifan dalam suatu pernikahan. Selain menjadi perhiasan, siger pun memiliki makna filosofis yang harus dimaknai agar mendapatkan kehidupan pernikahan yang rukun dan harmonis. Selain itu, siger Sunda dapat dikatakan sebagai suatu bentuk ekspresi dan penyampain pesan moral yang ada dalam lingkungan kehidupan budaya Sunda (Desiana \& Dienaputra, 2019).

Selanjutnya, ronce [roncc] yaitu sebutan untuk untaian bunga yang dikenakan pada siger. Ronce ini melambangkan sebagai kemurnian dan kesucian dari pengantin wanita Sunda. Panjang dari ronce ini berkisar sekitar 20 hingga 30 sentimeter dan terdiri dari beberapa bagian yang disebut mangle. Mangle tersebut dibagi menjadi beberapa meliputi mangle pasung, mangle susun dan mangle sisir. Mangle biasanya disusun dengan beberapa jenis bunga yaitu bunga melati, kamboja, tanjung atau sedap malam. Mangle susun merupakan untaian bunga yang diletakan memanjang di belakang telinga sebelah kanan, ukuran panjang dari mangel susun memiliki makna kultural sebagai adanya rencana urusan rumah tangga yang telah disusun dengan rapi. Mangle sisir merupakan hiasan bunga yang berbentuk seperti bintang yang dipasangkan di bagian sanggul bagian kanan dan kiri. Makna kultural dari mangle sisir yaitu seorang wanita memiliki harapan yang indah layaknya indahnya malam yang bercahaya di tengah gelapnya malam. Selanjutnya, mangle pasung yaitu hiasan yang berjumlah lima sampai tujuh buah yang dikenakan di sekeliling sanggul bagian atas yang membentuk setengah lingkaran lalu dipasang dengan berupa pinti yang bentuknya menyerupai bando dan dipasangkan di sekeliling sanggul. Pinti pada mangle pasung ini menyimbolkan atas kesucian seorang gadis.

Panetep bunga [panctcp buna] adalah penutup sanggul yang terbuat dari beberapa untaian bunga yang berbentuk bulat. Panetep bunga ini mempunyai makna kultural yaitu seorang wanita harus memiliki ketepatan dalam memutuskan suatu hal terutama dalam urusan rumah tangga. Mayangsari [mayan sari] yaitu untaian bunga yang berukuran pendek dan dipasangkan di telinga sebelah kiri. Dalam hal ini, mayangsari 
memiliki makna spiritual yaitu harapan atas rumah tangga yang harmonis dan tidak ada perselisihan di dalamnya.

Kembang goyang [kcmban goyan] adalah perhiasan yang dipasang di atas sanggul dan terbuat dari logam yang bermata batu-batuan. Jumlah dari kembang goyang ada tujuh buah, lima diantaranya akan dipasangkan mengarah ke depan sedangkan dua diantaranya disematkan mengarah ke belakang. Hal ini mengartikan bahwa seorang perempuan harus terlihat kecantikannya dari sisi depan maupun belakang. Adapun makna kultural dari kembang goyang yaitu rezeki dan inti kebaikan untuk kedua pengantin. Selanjutnya, kembang tanjung [kemban tanjun] yang disematkan di belakang siger dengan berbentuk pola seperti bentuk hati. Kembang tanjung terdiri dari rangkaian enam pasang kembang tanjung yang dipasangkan. Makna kultural dari kembang tanjung yaitu sebuah kesetiaan yang harus dijaga oleh pengantin putri kepada pasangannya.Wajit turih [wajit turih] adalah daun sirih yang dibentuk menyerupai wajit dan disematkan di kening pengantin wanita. Daun sirih sendiri merupakan lambang dari penolak musibah/bala. Makna kultural dari wajit turih yaitu sebagai kesetiaan dari seorang istri, kedewasaan dari seorang istri dan juga sebagai penolak bala dalam rumah tangga.

\section{KESIMPULAN}

Pernikahan adat Sunda khususnya di Priangan memiliki perhiasan pengantin Suda yang kaya akan makna kultural dan dipercaya sebagai doa serta harapan para leluhur dan masyarakat Sunda. Perhiasan pengantin Sunda meliputi gelung, mangle, siger, kembang goyang, kembang tanjong, giwang, bros, benten, Garuda mungkur, wajit turih, panetep, bunga Mayangsari, ronce. Secara kultural, tradisi ini dapat terlihat dari salah satu aspek spiritual yaitu menjadi harapan dan doa dari para leluhur dan masyarakat Sunda. Makan kultural dari setiap leksikon perhiasan pengantin putri Sunda Priangan adalah tentang kehidupan yang harus memuncak dan saling menjaga menghindari bala/musibah dalam kehidupan berumah tangga. Selain itu, makna kultural dalam perhiasan pengantin putri Sunda Priangan juga menggambarkan kehormatan, kesucian, kebijaksanaan, kesetiaan serta kecantikan yang terpancar dari berbagai sisi sosok Wanita Sunda. Penelitin ini focus pada makna leksikal dan dirasa masih kurang dan bisa dikaji dalam berbagai kajian ilmu.

\section{DAFTAR RUJUKAN}

Amelia, N. F., \& Syaifudin, A. (2020). Makna Kultural Dalam Satuan Lingual Rias Pengantin Pemalang Putri. Jurnal Sastra Indonesia, 184-191.

Desiana, F. I., \& Dienaputra, R. D. (2019). Akulturasi budaya Sunda dan Jepang melalui penggunaan Igari Look dalam tata rias Sunda siger. PATANJALA (Jurnal Penelitian Sejarah dan Budaya) Vo.11 No.1, 149-163.

Hardiyanto. (2008). Leksikologi : Sebuah Pengantar. Kanwa Publisher. 
Koentjaraningrat. (2005). Pengantar Antropologi Jilid II. PT. Rineka Cipta.

Lestari, R. D., \& Saripah, I. (2019). Strengthening cultural values through innovative learning of Sunda Siger bridal make up in West Java vocational education. 2nd International Conference on Arts and Design Education (ICADE 2019) (pp. 222229). Atlantis Press.

Moleong, L. (2005). Metodologi Penelitian Kualitatif. Remaja Rosdakarya.

Nirmalasari, Y. (2018). Pola kalimat bahasa Indonesia tulis pembelajar BIPA tingkat pemula asal Tiongkok di Universitas Ma Chung Tahun 2018. KLAUSA Journal of Linguistics, Literature, and Language Learning) Volume 2 No.1, 41-50.

Nirmalasari, Y. (2020). Pola argumen mahasiswa Jurusan Bahasa Mandarin. KLAUSA (Journal of Linguistics, Literature, and Language Learning) Vol. 04 No.1, 59-67.

Ramadhanty, N. R. (2019). elibrary Unikom. Retrieved June 19, 2021, from elibrary.unikom.ac.id:

https://elibrary.unikom.ac.id/view/creators/Ramadhanty=3ANur_Rizqa=3A=3A.ht $\mathrm{ml}$

Roveneldo. (2018). Kajian makna pada aksesori pakaian adat Lampung Pepadun. Sirok Bastra, 139-150.

Rudiyanto, Rais, W. A., \& Purnanto, D. (2020). Tinjauan etnolinguistik: Makna kultural dalam tradisi "Sranan" sebagai wujud kearifan lokal masyarakat petani pegunungan di Kebumen. Seminar Nasional Linguistik dan Sastra (SEMANTIKS) (pp. 543-552). Surakarta: Universitas Sebelas Maret.

Saifullah, A. R. (2018). Semantik dan dinamika pergulatan makna. PT Bumi Aksara.

Santosa, R. (2017). Metode penelitian kualitatif kebahasaan. UNS Press.

Sibarani, R. (2015). Pendekatan antropolinguistik terhadap kajian tradisi lisan. Retorika : Jurnal Ilmu Bahasa, 1-17.

Sugiyono. (2009). Metode Penelitian Kuantitatif, kualitatif dan R\&D. Alfabeta. 
142 | DOI: 10.33479/klausa.v5i02.432 